\title{
Ethics of the use of horses for sports
}

\author{
Elizabeth Atwood Lawrence \\ Tufts University School of Veterinary Medicine
}

\begin{abstract}
Summary
Partnerships between people and horses have a long history, and human relationships with horses are unique in many ways. The particular nature and behavior of the equine species make it vulnerable to painful and injurious exploitation, especially in sporting events that require so much effort and exertion on the part of the horse. Therefore it is urgent for veterinarians who practice in the field of equine sports medicine to establish and follow a code of ethics that would protect equine athletes. Because of the duality of their role in acting as agents of owners and trainers while simultaneously being advocates for their patients, veterinarians are often placed in a difficult position with regard to carrying out therapeutic programs and medical procedures that are favorable to the horse and yet acceptable to the people in charge of the animal. Once equine sports medicine practitioners unify in setting forth and adhering to ethical guidelines that allow them to favor the horse's welfare when there is a conflict of interest involving their patient, they will then be empowered to institute preventive and medical procedures that will be in the best interests of the horse.
\end{abstract}

Keywords: $\quad$ veterinary ethics, equine medicine, equestrian sports, welfare of horses, horse behavior

\section{Ethische Grundsätze beim Einsatz von Pferden im Sport}

Partnerschaften zwischen Menschen und Pferden haben eine lange Geschichte und die Beziehung zwischen Mensch und Pferd ist auf vielerlei Art und Weise einmalig. Sein besonderes Wesen und Verhalten machen das Pferd durch schmerzvolle und schädliche Ausnutzung, besonders bei sportlichen Ereignissen, die so viel Anstrengung und Bemühungen von Seiten des Pferdes verlangen, verwundbar. Darum ist es für Tierärzte, die im Bereich der Pferdesportmedizin praktizieren, dringend notwendig, einen ethische Grundsätze zu erstellen und zu befolgen, die den Athleten Pferd schützen. Tierärzte handeln zum einen als Agenten von Besitzern und Trainern und sind zugleich auch die Fürsprecher ihrer Patienten. Wegen der sich daraus ergebenden Dualität ihrer Rolle befinden sich Tierärzte oftmals in einer schwierigen Position in dem Sinne, daß sie therapeutische Programme und medizinische Behandlungen durchführen, die zum einen von Vorteil für das Pferd, zum anderen für die für das Tier verantwortlichen Personen akzeptabel sein müssen. Wenn sich in der Pferdesportmedizin tätige Tierärzte zusammenschließen, um ethische Richtlinien zu erstellen, die es ihnen erlauben, der Gesundheit des Pferdes Vorrang zu geben, und diesen treubleiben, dann werden sie fähig sein, präventive und medizinische Verfahren zu etablieren, die im Interesse des Pferdes sind.

Schlüsselwörter: Ethik der Tiermedizin, Pferdemedizin, Reitsport, Tierschutz, Verhalten

Human relationships with horses - in their many complex and varied forms - have profoundly affected human life and culture. Indeed, the special bond that exists between people and horses has often influenced the course of history. Exploitation of the equine's tremendous potential for supplying power brought undreamed-of benefits to early civilizations and made the horse an indispensable partner in human endeavors. Domestication and use of the horse transformed human existence with the harnessing of its strength and swiftness to provide mobility. Because of its magnificent contributions to human welfare and concerns, the horse became interwoven with cultural and recreational spheres of life as well as utilitarian purposes. That horses have been almost universally held in high regard is not difficult to understand, for "learning to control such a remarkable beast was probably the most exciting development in man's history, next to the invention of the wheel" (Hope and Jackson 1973:236).

Horses confer a feeling of heightened self-worth that is reflected in the behavior and perceptions of people who interact with them.
Both in a literal and symbolic sense, horses elevate the status of those who ride and use them. Through the ages the horse has been "the symbol of superiority, of victory and triumph," placing his rider "as much above himself and others as the world can make him" (Webb 1936: 493). Equestrians are literally and figuratively "looked up to," and the pride and arrogance attributed to the mounted state is perpetuated in the common expression "get off your high horse!" Historically, horses have often been considered the noblest of domestic animals who somehow confer the equine traits of dignity and refinement, grace, beauty, and power on their human associates. The prestige that society grants to the horse persists into modern times, for the aura of equine grandeur remains to grace the machine age.

Today there are probably as many horses in the world as existed during the ages when people depended upon them for transportation and traction. Whereas horses were once owned by necessity and for utility, they are now acquired by choice for pleasure. The prevalence of horses as companions in recreation and partners in 
sport is testament to their enduring appeal and cultural value. Motion is a quintessential element of the human-horse bond. Horse races reward the swiftest runners with the accolades of society; hunters and jumpers leap over hurdles according to complex patterns; and rodeo bronc riders gear their body rhythms to their wildly bucking mounts. There is kinetic interaction between equine and human bodies as well as merging of wills through reciprocal channels. Fine-tuned intercommunication between rider and horse is both physical and mental. Thus horses are companions of a different order than most other animals and human/horse relationships are virtually unique.

To understand the contemporary use of horses for sport and provide the appropriate ethics for interaction with them, it is necessary to consider the horse's basic nature and behavioral characteristics. The fact that a large, gentle herbivore whose natural reaction to danger is flight could be made to gallop forward into the noise and confusion of battle demonstrates the same traits of willingness and obedience that are present in the sport horses of today. Innate herd behavior and adherence to social dominance orders play a large part in the equine propensity to cooperate with human partners. The rider in a sense takes the place of the horse's conspecifics, and thus the animal is disposed to do the bidding of its human counterpart. Potential for dynamic interaction between people and horses arises from the highly social nature of both the equine and human species, and fosters the development of a unique complementariness.

Need for the company of other horses is inherited and the social acceptance necessary for each horse within a herd is similar to the approval that it needs from its rider or handler. As international authority on equine communication Henry Blake points out, in addition to the security of being a member of a group, it is also essential for a horse's well-being to think highly of itself. The horse with the most self-esteem will rise in the social hierarchy and a winner in sport events must have the same self-confidence in order to strive to do its best. In asserting itself over other horses to obtain power within the herd, a horse may gallop faster than other herd members or surpass them in jumping fences. According to Blake, "this ambition can be channeled to get the horse to succeed in competition," so we should "go to great lengths to build up a horse's self-esteem when we want it to compete." The urge to excel has been inherited from ancestral equines, „since the horse that was the biggest, strongest, fastest, and mentally dominant was the one that had the best grazing and was the best able to escape from any predators. ... If you remove pride from a horse, you will remove his will to win.... That is why a horse that has been broken and cowed will never be so good a horse as one who has been allowed to develop slowly and naturally" (1986: 306-309).

The horse represents a strange paradox with its great strength combined with tractability. Horses have an innocent quality that is expressed by their trust in and submissiveness to their trainers and riders. The horseman's expression that a mount has a "kind eye" encapsulates the phenomenon of a creature of enormous power who typically harbors such benevolence toward people. And "horse sense" remains a quality as highly respected as „horse power." When contrasted with other species that have been utilized for transportation, such as camels and donkeys, who will generally rebel if too much is demanded of them, the horse's compliant nature becomes even more clear. Typically, the horse will overcome its instincts for self-preservation to conform to the human will that has been imposed upon it. Responding to its rider's urging, a mount will often surmount its own distress to the point of undergoing pain, injury, and even death to accomplish a goal. Because of their sensitivity and unusual predisposition to devote themselves fully to the tasks demanded of them, horses are particularly vulnerable to over-exploitation and cruelty. Thus the urgent necessity for special ethical concerns regarding equine partners in sport, who are asked to exert themselves so intensely, springs out of the horses' nature itself, and represents profound challenges to people who have responsibility and accountability for the animals' welfare. Preeminent among those who have this ethical obligation are the veterinarians who oversee the health of sport horses, in both preventive and therapeutic programs. Veterinary medicine entails a unique duality, requiring its practitioners to be advocates of their animal patients and simultaneously to act as agents of their owners or trainers. Divided loyalties and the conflicting interests of animal and owner complicate the role of the veterinarian and often impose difficult choices. But as a mediator between animals and people, the veterinarian must take on the duties of teacher as well as medical practitioner. Because of their career choice and their specialized training and knowledge, equine veterinarians are generally perceived by the public as „horse experts." This honored status can be used to instill appreciation of horses' contributions to society - past and present - as humankind's closest ally and working partner, and to teach people to respect the ambitious equine spirit while recognizing the limits of the animals' physical capabilities and their susceptibility to pain. As animal advocates, protection of the welfare of horses should be the natural concomitant of the practitioner's skill and understanding not only of equine physiology, but of the species' developmental history and behavioral traits. Veterinarians can promulgate the idea that in addition to physical conditioning the confidence that handlers can confer on their mounts through patient and humane training will help to create a winning horse.

In assessing the ethical aspect of equine sports medicine, it is vital to distinguish between publicly displayed, as opposed to privately inflicted, cruelty to equine athletes. For example, to the average spectator, treatment of rodeo broncs appears grossly inhumane, as they are cinched with a flank strap and spurred, while interactions with graceful Tennessee Walking Horses or five-gaited Saddlebred Horses in the show ring seem begin. Yet these observations are not necessarily accurate, for the bronc undergoing 8 seconds of obvious pain while in the arena could suffer far less, overall, than the show horse who, isolated in a stall, may suffer months and years of torture from being confined in head and tail sets and might endure agony from weighted shoes and painful devices applied to feet and legs to alter or enhance its gaits. Behind-the-scenes whippings can result in the illusion of "spirit“ demonstrated in the show ring when the whip is raised. Judgments about cruelty involve cultural and psychological factors that vary among individuals. As my rodeo fieldwork data reveal, contestants feel that the confinement of horses characteristic of eastern horse management is a much greater evil than their own seasonal use of broncs who are likely to spend the remainder of the year free on the range (see Lawrence 1984). Comparing one form of cruelty to another does not make one right and the other wrong these examples demonstrate only that measurements of inhumane treatment must take into account 
all phases of the horses' lives - hidden and revealed - not just what is evident to the public or even what is superficially obvious to the veterinarian.

It is easy for the equine sports practitioner to become preoccupied solely with the technicalities of preventive regimes, diagnostic techniques, and therapeutic programs to improve or restore the performance of equine athletes. Research and experience continue to produce many new and exciting developments in equine sports medicine to enrich this field of practice, affording substantial benefits to patients, and giving pride and a sense of fulfillment to practitioners. But there is a factor, familiar to everyone here today, that can mar this gratifying progress and accomplishment. This is the idea that somehow equine veterinarians are under the control of the trainers and owners who hire them and must practice medicine as those people dictate. This situation is unlike that of most health professionals, whose knowledge and skill almost certainly determine forms of human therapy. William Jones, author of the book Equine Sports Medicine, described the power trainers have typically held over veterinarians, pointing out that "in many cases, trainers simply told veterinarians how to treat their horses and the veterinarians either complied or found themselves without clients at the track" (1989:1). This is an old story that persists: I was warned about it in veterinary school when I wanted to be an equine practitioner, I have heard it from colleagues who set out to be horse practitioners but were deterred by it, and I still continue to learn about it from those who practice equine medicine today. Contemporary veterinarians must face and overcome this long-standing obstacle that impedes the effective and ethically sound practice of equine sports medicine and stands in the way of the patients' recovery, health, and welfare.

„When owners, trainers, and veterinarians establish mutual respect and cooperation, the horse comes out ahead" (Jones 1991:6). By establishing outstanding reputations in their field practitioners will achieve the autonomy necessary to practice effective medicine. A prime requirement is a positive self-image; if veterinarians possess the appropriate awareness of the values and strengths of the profession, as well as confidence in their own integrity, knowledge, skill, and commitment, this assurance will lead to deserved faith in both the profession as a whole and in its individual practitioners. Thus I would argue that understanding the history of veterinary medicine, with its many accomplishments that benefit both people and animals, is closely tied to veterinary ethics. Knowledge of recent and past medical advances leads to individual practitioners' pride and earns society's respect for the worth of the profession and the unique abilities of its members. Self-confidence will result in clients' faith in practitioners' diagnoses and proposed treatments, so that equine veterinarians can afford to show the courage to insist upon the therapies they know are indicated and to resist pressures to conform to the dictates of owners or trainers. In order to accomplish this, of course, veterinarians must stand together, support each other with collegiality and solidarity in advocacy of the patient, and institute medically indicated treatment following diagnosis. If one veterinarian refuses to carry out therapy ordered by a layperson that is not in the sport horse's best interest, and another practitioner is willing to take over in following that faulty regime, little can be accomplished to give ethics the firm foundation that it needs.

One writer states that „when the history of veterinary medicine for this century is written, it will show that the 1980s were the times of the development of equine sports medicine" (Jones 1991:7). Now it is essential to make the 90 s the time of establishing ethical standards in that field for the new millennium. According to an overview of equine sports medicine, this veterinary specialty has passed "out of its infancy" and is presently "in its adolescence" (Rose and Hodgson 1994:4). Now its practitioners must work to develop the field to full maturity by recognizing, confronting, and acting upon the moral responsibility that it entails. In equine sports medicine the need for a code of ethics is especially urgent. The nature of horses themselves and the demanding tasks imposed upon them predispose to over-exploitation leading to pain, injury, and death. Conflict between the welfare of the horse and the people who stand to profit from its winning may present acute dilemmas for the veterinarian, who bears the heavy burden of deciding the athletic capabilities of the patient as well as the responsibility of overseeing its health and instituting therapy. Often consideration for the horse rather than for the immediate benefit of its owner or trainer dictates that palliative treatments must be avoided because they would ultimately lead to further injuries for the animal.

Although ethics should be an integral part of equine sports medicine, little if any attention has been devoted to this aspect of practice in professional books or articles dealing with this important area of specialization within veterinary medicine. Popular publications are no different. The Horse in Sport, co-authored by an equestrian Olympic champion (Steinkraus and Stoneridge 1987), for example, describes in detail nine major equine sports and several smaller equestrian events, yet provides no coverage of humane considerations or ethics. Hopefully that void will soon be a thing of the past and sports medicine veterinarians will organize to lead the way in establishing a code of ethics that will benefit the profession as well as the clients it serves, and most importantly, protect the patients - the equine athletes who are such willing courageous, talented, and hard-working partners in sport.

\section{References}

Blake, H. (1986): Horse Wisdom, London: Souvenir Press.

Hope, C. E. G. and Jackson, G. N., eds. (1973): The Encyclopedia of the Horse. London: Peerage Books.

Jones, W. E. (1989): Equine Sports Medicine. Philadelphia: Lea and Febiger.

Jones, W. E. (1991): .Sports Medicine for the Pace Horse. Second edition. Wildomar, CA: Veterinary Data.

Lawrence, E. A. (1984): Rodeo: An Anthropologist Looks At the Wild and the Tame. Chicago: University of Chicago Press.

Rose, R. J. and Hodgson, D. R. (1994): An Overview of Performance and Sports Medicine. Philadelphia: W. B. Saunders.

Steinkraus, W. C. and Stoneridge, M. A. (1987): The Horse in Sport. New York: Stewart, Tabori and Chang.

Webb, W. P. (1936): The Great Plains. Boston: Houghton Mifflin Company.

\section{Dr. Elizabeth Lawrence}

Po Box 35

Adamsville, Rl 02801

USA 